\title{
Development of a briquetting facility with the integration of a hydraulic system for biomass densification
}

\author{
L. M. Gan, H. C. Law \& A. B. Rosli \\ Faculty of Mechanical Engineering, Universiti Malaysia Pahang, \\ Malaysia
}

\begin{abstract}
Biomass is recognized as a promising source of energy for replacing the utilization of fossil fuels in the near future. As to ensure the availability of biomass for a variety of applications, the challenges in feeding, handling, storing and transporting with the use of biomass wastes in original form must be resolved. Briquetting is one of the densification methods opted to transform the bulky biomass into valuable and manageable products for energy generation. However, the expansion of biomass briquetting depends on the appropriate technologies to accommodate the requirements for briquette formation. As found in recent studies, the existing commercialized briquetting facilities are meant for mass production in industries and there are limitations, making them less compatible with the research purposes. As a result, a small-scaled briquetting facility with reasonable production cost integrating the simple hydraulic working principle had been designed and realized. The hydraulic system would be an additional benefit whereby less effort is required in the operation. On the other hand, the main components in the facility, namely piston and mold, were custom-made. The complete assembly of the facility was then tested using various types of biomass resources, for instance, ground papaya leaves and sawdust. The testing was mostly conducted at a compacting pressure of 300 bars and, hence, resulted in the generation of briquettes resembling a bowl shape. The perfect shape of bowls indicated the effectiveness of the facility.

Keywords: biomass, densification, briquetting, briquetting facility, hydraulic working principle, compacting pressure.
\end{abstract}




\section{Introduction}

Biomass is naturally abundant and biologically originates mainly from plant material and animal wastes that could serve primarily as domestic energy source in rural communities [1]. In Malaysia, a minimum of 168 million tonnes of biomass wastes is generated annually [2] and thus providing a renewable energy opportunity for power electricity generation in near future. As proposed in the $10^{\text {th }}$ Malaysia Plan, renewable energy including biomass is targeted to account for $5 \%$ of the total capacity mix in 2015 to reduce dependency on fossil fuels [3]. On the contrary, the utilization of biomass in its original form often associates with the problem of feeding, storing, handling and transport.

Briquetting technology, one of the densification methods is thus introduced to manage the loose, bulky and dusty wastes efficiently. Briquetting is defined as a process undergoing compaction of residues and pressure is applied with or without a binder to convert the wastes to a compact agromate [4]. However, the expansion of biomass briquetting depends on the implementation of appropriate technologies to accommodate the briquette generation. Attempts in the development of briquetting devices, adopting different principles have been carried out by researchers to have sufficient supply of briquettes for conventional use.

Studies show that hydraulic piston presses, one of several types of equipment, are commonly adopted for biomass briquetting as the energy transmitted to the piston is through the electric motor via high-pressure hydraulic system [5]. However, the existed briquetting facilities are not suitable for research and laboratory experiment use, but more towards industrial application. By taking the advantages of the hydraulic system as the working principle, a more appropriate briquetting facility or densifier is developed in accordance to the requirements of briquette formation for experiment in this project. The performance of the facility is only evaluated after completing the installation.

\section{Benchmarking of briquetting mechanism}

There existed a first version of the briquetting prototype incorporating the screw press technology, as illustrated in Figure 1. However, there were weaknesses on the design as the compression piston was unable to withstand the high exerted pressure during the compression. The movement of the briquetting mold was against the gravitational attraction during compression. Hence, higher forces or pressure were required from the electric motor to move the mold upwards which was not an ideal solution.

In a nutshell, benchmarking for the design of the new briquetting facility, also known as densifier, was summarised by taking the weaknesses and strength of the existing prototype into consideration. The existing prototype acted as a reference and at the same time the parameters such as maximum exerted pressure, pressing or compression mechanism were considered in the latest briquetting facility. 


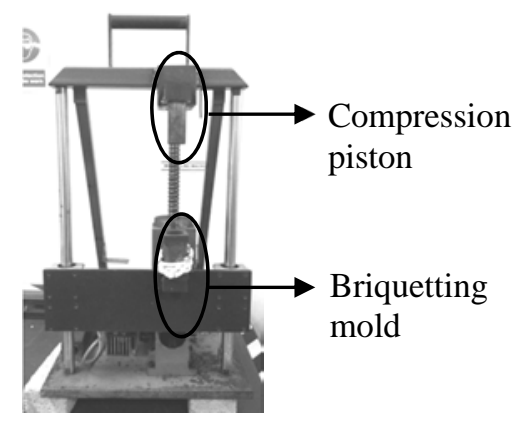

Figure 1: Briquetting prototype.

Nevertheless, a manually operated hydraulic press as displayed in Figure 2 was readily available, consisting of the necessary components for hydraulic system. Hence, the development of the latest briquetting is based on the specifications of the hydraulic press, integrating a simple manually operated hydraulic system as well as vertical compression method in downward movement.

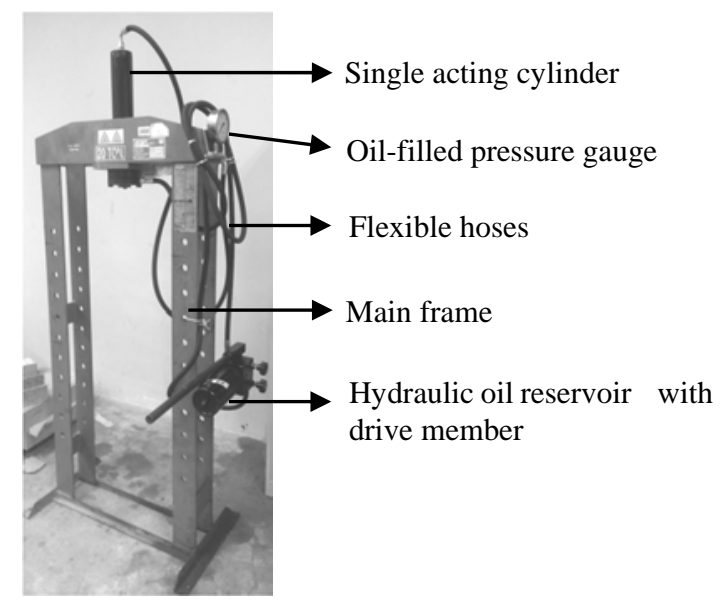

Figure 2: Existing hydraulic press with hand pump.

\section{Operating principles}

\subsection{Concept of vertical compression method}

With the concern regarding to the quality of the briquette produced in terms of strength and durability, vertical compression method was opted as the principle of operation for the briquetting facility due to some outstanding benefits. On top of that, the availability of the hydraulic press with an installed single acting cylinder in vertical direction has also contributed to the initiation of this particular concept. 
The concept of vertical compression method was employed since the gravitational force would support the cylinder to extend downwards smoothly. The cylinder piston was originally located in the vertical direction in which the cylinder would extend downwards and retract upwards. This then caused the compressive forces exerted in the vertical direction to be high enough to obtain briquette with adequate strength. On top of that, this downward movement also eased the filling of loose biomass into the densifier mold besides the following collecting job.

\subsection{Hydraulic system and control mechanism}

The hydraulic system was completed with the installation of a single acting cylinder, oil-filled pressure gauge as well as hydraulic oil reservoir with its drive members including the pump driving lever, speed gear valve, stem return valve. All the elements were interconnected using hydraulic transmission lines or flexible hoses, through which the hydraulic liquid would flow. The hydraulic press could withstand up to a capacity of 200 tonnes and a maximum compression pressure of 500 bars. The oil-filled type pressure gauge with maximum pressure of 400 bars as displayed in Figure 3 was thus installed to record the pressure and ensure that the compressing pressure is within the range during briquetting process.
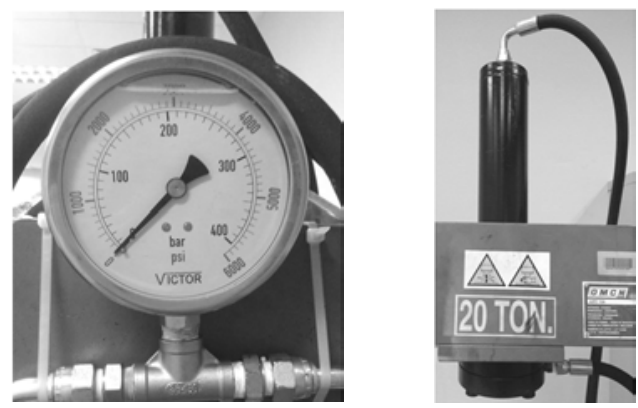

Figure 3: Oil-filled type pressure gauge (left) and single acting cylinder with spring return valve (right).

The installation of the hydraulic system and the fixing jobs must be done cautiously by following the sequences as to ensure a secure system without leakage. First and foremost, the functionality of the single acting cylinder had to be checked. The piston cylinder as portrayed in Figure 3 and oil reservoir in Figure 4 were then secured in place using bolts and nuts. The subsequent step involved the preparation of the connecting hoses, either utilizing $90^{\circ}$ flexible hoses or straight bend. The first connection was between the reservoir and pressure gauge, the second between the pressure gauge and the cylinder, and finally the third between the outlet of the cylinder and the reservoir. The connecting hoses were only installed accordingly after the application of white tape in the joints as to minimise leakage in the long run. Finally, the hoses were then arranged in a proper manner and fixed to the frame. 


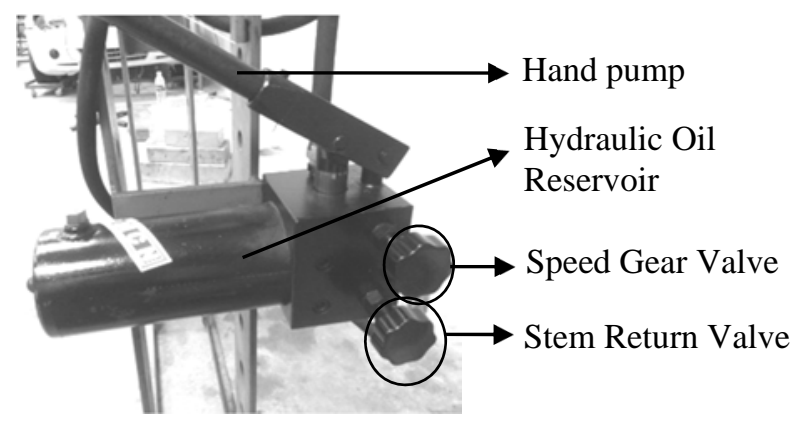

Figure 4: Hydraulic oil reservoir with drive members.

On the other hand, the reservoir was half-filled with the Pennzoil AW Hydraulic Oil ISO 32 that would be recycled during the retraction process. Therefore, the reservoir was not fully filled as the phenomenon would result in overflowing, prompting damages to the system. After that, the bleeding process was required in the system before the hydraulic press could be operated in order to get rid of air bubbles as only hydraulic fluid was allowed in the system. The process to pump the fluid from the reservoir to the cylinder was carried out a few times. Each hose was loosened and checked for the oil flow, where the speed gear valve needed to be closed in order to obtain a high speed flow. The pumping work was continued until there was outflow of oil, indicating no more air bubbles inside the hoses. Subsequently, the hoses were tightened. This crucial step shall be applied to all hoses involved since the oil flow may affect the movement of the cylinder. After the bleeding process, the hoses must be tightened up and ensured no leakage. Then only the hydraulic system would be considered as complete and functional.

The briquetting process incorporated the simple hydraulic system control mechanism. Firstly, the bottom control valve or stem return valve allowing the flow of hydraulic fluid from the reservoir to the cylinder, also the speed gear valve which helped in accelerating the fluid flow, were closed. The hydraulic mechanism enabled effective extension and retraction of the cylinder. The actuation would need to be done cautiously due to exerted pressure. It would then be terminated when the desired compressing pressures had been achieved, through the readings shown in the pressure gauge. Once the stem return valve was loosened, the cylinder would retract slowly to its original position, with the help of the spring embedded within the system.

The use of hydraulic system was meant to ease the compressing job on the densifier. Higher compressing pressure could be achieved with lesser effort with the aid of the hydraulic system. For this model of hydraulic press, none of the power supply was required during the operation, thus it was convenient for the experiment to be carried out anytime and anywhere. 


\subsection{Design on the components for briquetting process}

Refinements were required on the existing hydraulic press to accommodate the changes in the objectives. Hence, five other necessary components namely piston, piston guider, bottom pin with locking plate and densifier mold were designed and custom-made based on the specifications and requirements of the hydraulic press. There was also a minor modification on the existing fixing bar with the addition of 8 holes in the middle portion fitted with the mold, as displayed in Figure 5.
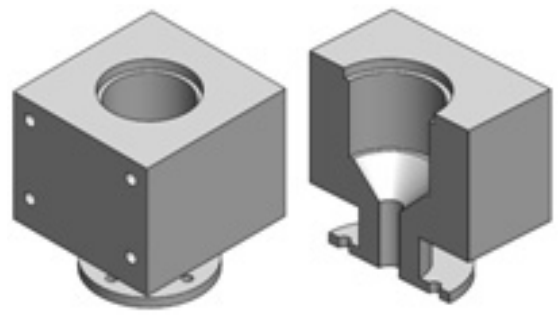

(i)

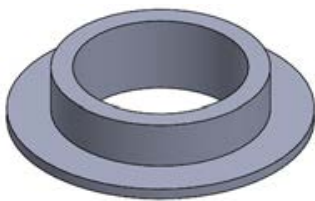

(iii)

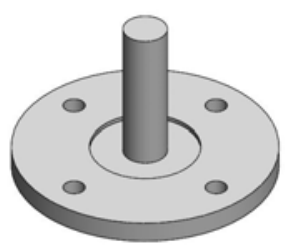

(iv)

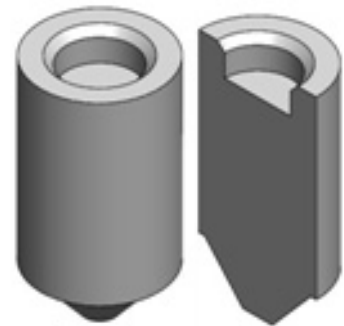

(ii)

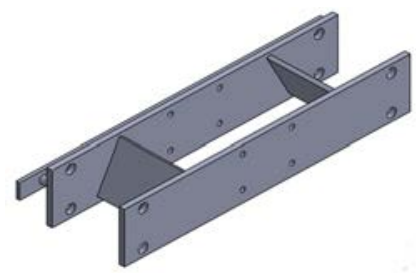

(v)

Figure 5: (i) densifier mold; (ii) densifier piston; (iii) piston guider; (iv) bottom plate with locking pin; (v) modified fixing bar.

As seen in Figure 5, the densifier piston, mold, piston guider and the bottom pin with the locking plate using latest technology were meant to produce briquettes resembling the shape of a bowl with a certain extent of depth. So, the dimensions of the piston mold and other components were decided based on the existing hydraulic pressure as well as diameter of the existing single acting cylinder.

All these particular components were made in solid stainless steel particularly the densifier mold and piston to withstand higher compressive forces during the briquetting process. The piston and mold were designed to be detachable to ease the removal of the briquette, minimising damage, also easing the cleaning task after each compression process. Figure 6 illustrates the exploded view for the arrangement of vertical installation of the components involved. 


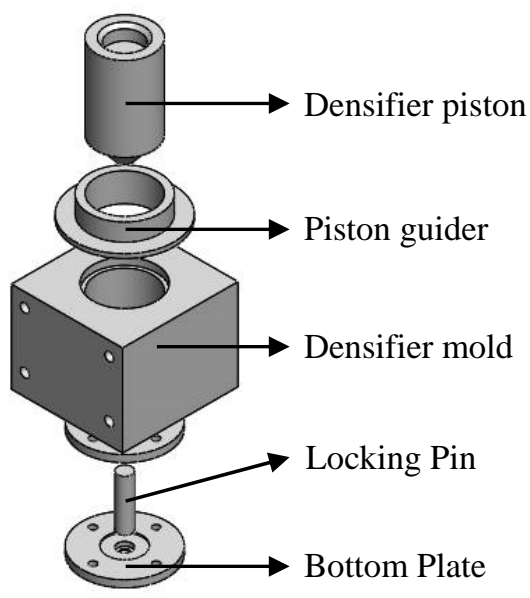

Figure 6: Exploded view on fabricated elements installation.

\subsection{Standard operating procedures}

1. The bottom plate with the locking pin was installed to the densifier mold.

2. The specimen was then poured into the cavity of the mold cautiously.

3. The piston guider was fitted to the mold, followed by slitting in the piston slowly until the maximum height was achieved.

4. A hollow steel bar was located on top of the piston.

5. Both the speed gear valve and stem return valve on the oil reservoir were tightened up, and the hand pump was actuated continuously until the piston cylinder touched the bar.

6. Actuation of the piston cylinder was then performed in a slow manner until the desired pressure recorded in the pressure gauge was achieved.

7. The pressure holding time was set to be 20s before the piston cylinder retracted to the original position.

8. After 20s, the stem return valve was loosened and tightened back again within a few seconds after the piston cylinder retracted.

9. Step 5 to 8 was repeated for another 4 times to result in good binding.

10. Lastly, stem return valve was loosened fully and piston retracted, the bottom plate with the locking pin was taken out prior to the removal of piston guider and piston from the mold.

11. Once the whole process was accomplished, the briquette was extracted slowly and carefully from the mold with aid of locking pin.

\section{Findings}

Installation of the fabricated components to the main frame indicated a complete system to the briquetting facility, as portrayed in Figure 7. An exploded view on the facility is depicted in Figure 8. 


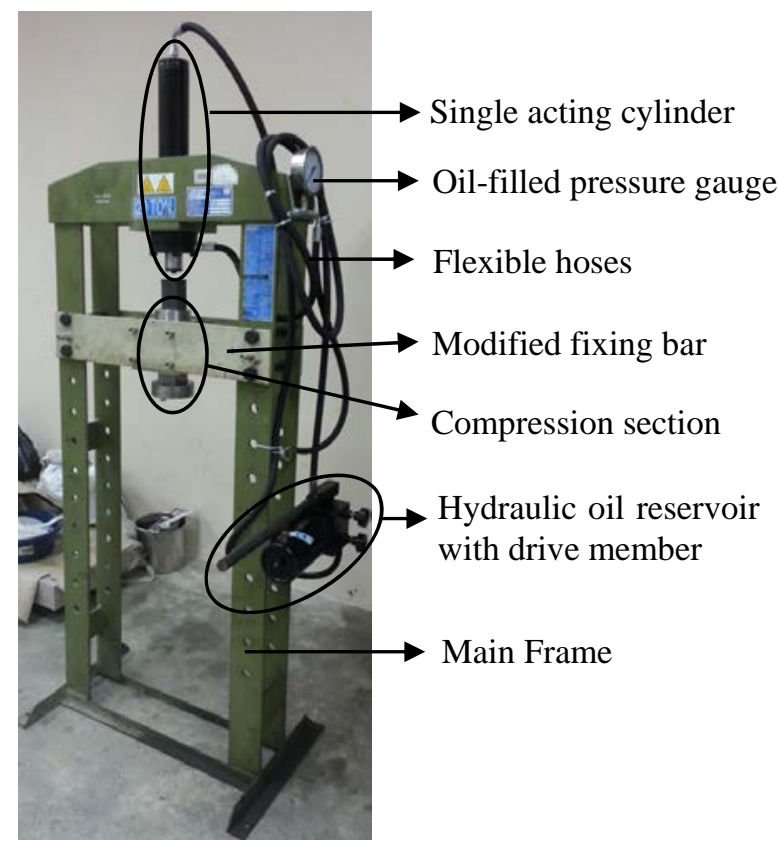

Figure 7: Briquetting facility or densifier.

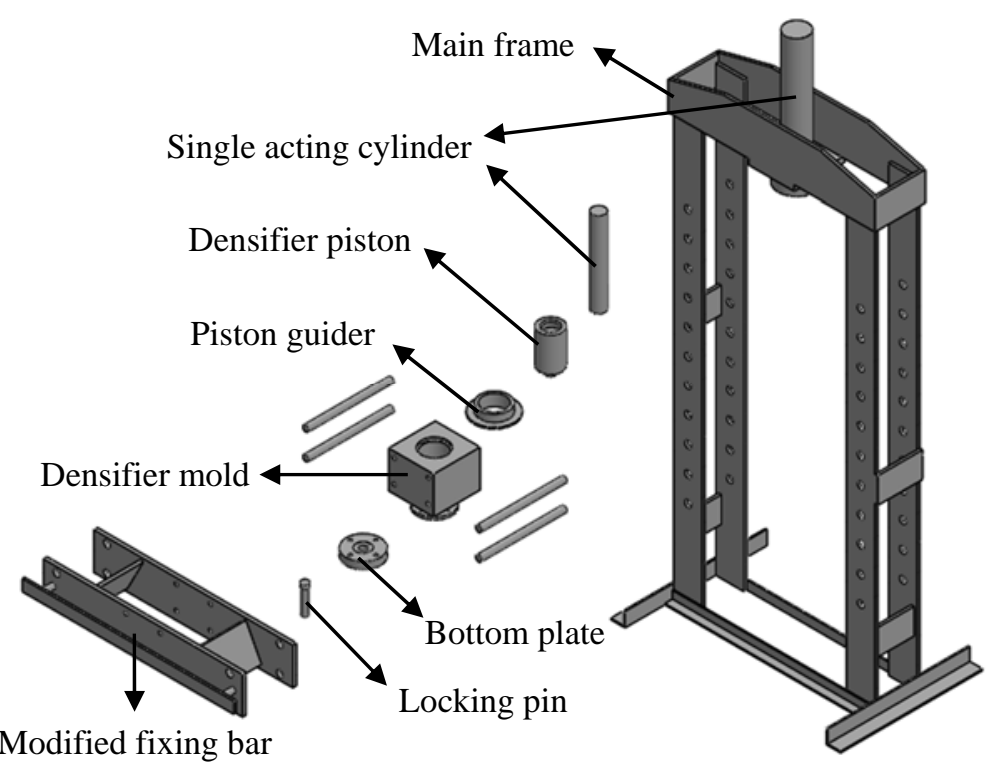

Figure 8: Exploded view of briquetting facility. 
With the utilization of the latest facility, the briquette formed was in a small bowl-shape with adequate strength as displayed in Figure 9. The plant combination opted for this particular briquette is papaya leaves and sawdust.

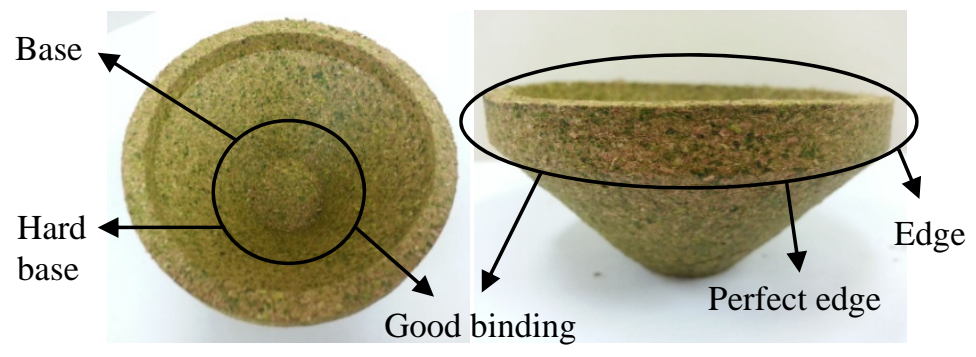

Figure 9: Briquette formed.

\section{Discussions}

The concept of vertical compression method was employed in the development of briquetting facility, also including a simple hydraulic system in operation, without power source. The performance of this particular design has been tested in the briquette formation at the initial stage and a satisfactory quality of briquette has been produced.

In the concept of vertical compression method, once the lever was pumped continuously, the piston cylinder would extend downward. This downward movement caused the hollow bar attached to the densifier piston also to move downwardly. Thereafter the pistons squeeze the powder into the mold. Due to this compaction, biomass powder particles deform and interlock. Hence binder was not required for a briquette to be formed. The compresses powder remained intact and took the shape of the mold.

Through the incorporation of the hydraulic system in the facility, the concept of vertical compression was much more appropriate whereby the cylinder could be extended in the downwards direction without having to apply much force through the motivation of gravitational force. Moreover, this particular vertical design eased the filling of loose biomass into the densifier mold to avoid damage caused to the specimens besides the following collecting job.

Specifications of the briquetting facility are listed as follows:

1. Small scale and portable

2. Do not require power source supply

3. Low production and installation cost

4. Simple and manageable operation

5. Availability of spare parts

6. Easy to be maintained, can be handled by unspecialized manpower

7. Ergonomics and free from noise pollution

8. Good strength and durability

A small scale briquetting facility is developed to ease the placement and for the easy handling purpose as well. On top of that, it is portable since there is none of 
power source supply required in operation, but with only manpower. As compared to the existing products in the market, the production cost for a unit of briquetting facility or densifier is considered low and in acceptable range. Hence, it would be an ideal suggestion for the small scale production for household usage due to its simple and manageable operation. The facility is easy to be maintained with the availability of the spare parts.

Apart from that, the height of the system accommodated the human standing height which taking the principle of ergonomics into account and therefore giving advantage to the machine operator, inducing easy controlling. The components for the compression were made in solid stainless steel to withstand the high exerted pressure from the piston cylinder in addition to corrosion resistant when dealing with the residues with higher moisture content. Detachable components are induced to ease the modification jobs if necessary.

\section{Summary}

At the end of this project, a briquetting facility with the integration of simple hydraulic system as well as vertical compression concept was developed in line with the specifications required in biomass briquette formation. As discussed, the performance of the facility has been validated with the production of the briquette with adequate strength which resembled as a bowl shape.

\section{Future work}

Improvements can be done on the briquetting facility and subsequently the structure of the solid fuel produced since the custom-made components are detachable. For the facility especially the densifier piston and mold, modifications were required in order to allocate the heating elements in the mold part for the involvement of compressing temperature. On the other hand, cylindrical structure was suggested to replace the bowl shape briquette, as to reduce the amount of materials needed and the ability for mass production within a shorter period.

\section{Acknowledgements}

I would like to express my heartiest appreciation to my supervisor, Dr. Gan Leong Ming for his continuous guidance. A special thanks goes to my partner, Ms. Gan Hui Leng for her encouragement and support.

\section{References}

[1] Obi, O. F., Adeboye, B. S., Aneke, N. N., \& Oke, E. 2014. Biomass briquetting and rural development in Nigeria, 3(3), 1043-1052.

[2] Nurhidayati A.A. \& Leon K.M. 2012. Malaysia's biomass potential. BE Sustainable Magazine. 
[3] Performance Management \& Delivery Unit (PEMANDU). 2013. Oil, Gas and Energy NKEA Fact Sheet. Retrieved on 13 ${ }^{\text {th }}$ October 2014 from http://etp.pemandu.gov.my/upload/NKEA_Factsheet_Oil_Gas_Energy.pdf

[4] Manickam, I. N., Ravindran, D., \& Subramanian, P. 2006. Biomass Densification Methods and Mechanism. Cogeneration \& Distributed Generation Journal, 21(4), 33-45, doi: 10.1080/15453660609509098.

[5] Tumuluru, J. S., Wright, C. T., Hess, J. R., Kenney, K. L., \& National, I. 2011. A review of biomass densification systems to develop uniform feedstock commodities for bioenergy application †, 683-707, doi: 10.1002/bbb. 